\title{
Intervenção Judicial em Políticas Públicas e o caso relativo à saúde: parâmetros para a concessão de medicamentos não listados pelo SUS, sob análise dos julgamentos do Supremo Tribunal Federal e do Superior Tribunal de Justiça
}

\author{
Judicial Intervention in Public Policies and the case related to \\ health: parameters to the concession of medicines not listed by \\ SUS, under analysis of judgement by the Supreme Court of \\ Justice and Federal Supreme Court
}

\author{
Artenira da Silva e Silva ${ }^{1}$
}

Edith Maria Barbosa Ramos ${ }^{2}$

Letícia Moreira De Martini ${ }^{3}$

\begin{abstract}
RESUMO:
O presente artigo tem por finalidade o estudo acerca da intervenção judicial em políticas públicas, vinculando-o ao entendimento proferido em decisões do Supremo Tribunal Federal e do Superior Tribunal de Justiça, relativas ao direito fundamental social à saúde, no que se refere à concessão de medicamentos não listados pelo SUS. Como pressuposto de análise, parte-se de um discurso valorativo adotado no bojo dos novos paradigmas da jurisdição constitucional, cujo foco de proteção deve propor o alinhamento junto a elementos lógicos, capazes de promover a racionalização dos argumentos jurídicos. Com isso, busca-se evitar o extrapolamento do ativismo judicial, resvalando em possíveis arbitrariedades dos juízos na condução de políticas públicas. Em verdade, o ativismo judicial deve nortear-se pela necessidade de controle do cumprimento das metas administrativas, dando ênfase à efetividade dos comandos constitucionais, aliados à razoabilidade de consecução do bem jurídico pretendido. Esse aporte teórico fundamenta a análise do caso da saúde aqui tratado, o qual enseja a estipulação de parâmetros equilibrados pelos tribunais superiores, capazes de ponderar entre os limites da
\end{abstract}

\footnotetext{
1 Pós-doutoranda em Direitos Humanos na Universidade Federal do Pará (2019). Pós-doutora em Psicologia e Educação pela Universidade do Porto/Portugal (2014). Graduada em Psicologia pela Pontifícia Universidade Católica de São Paulo. Mestre em Saúde e Ambiente pela Universidade Federal do Maranhão (2000). Doutora em Saúde Coletiva pela Universidade Federal da Bahia (2005). Atualmente é docente e pesquisadora associada da Universidade Federal do Maranhão e consultora em violência doméstica e proteção de direitos infanto-juvenis. Professora convidada de Universidades portuguesas e espanholas.

2 Pós-Doutora em Direito Sanitário pela Fundação Oswaldo Cruz - FIOCRUZ/Brasília/DF. Doutora em Políticas Públicas pela Universidade Federal do Maranhão. Mestre em Direito pela Universidade Federal de Minas Gerais. Graduada em Direito pela Universidade Federal do Maranhão. Professora do Departamento de Direito da Universidade Federal do Maranhão. Professora e Vice-Coordenadora do Mestrado em Direito e Instituições do Sistema de Justiça da Universidade Federal do Maranhão. Coordenadora do Núcleo de Estudos em Direito Sanitário (NEDISA/UFMA). Professora e Pesquisadora da Universidade do CEUMA - UNICEUMA.

${ }^{3}$ Possui graduação em Direito pela Universidade Federal do Maranhão (2010) e especialização em Direito e Processo do Trabalho pela Universidade Estácio de Sá (2017). Atualmente é Técnico de Gestão Administrativa Advogado da Assembleia Legislativa do Estado do Maranhão. Tem experiência na área de Direito, com ênfase em Direito Público.
} 
intervenção judicial e a necessária prestação do direito fundamental invocado, observando-se o grau de autonomia administrativa a ser preservado. A metodologia empregada consiste em pesquisa bibliográfica, documental e jurisprudencial, além da utilização da análise de conteúdo para dar significado aos dados colhidos.

\title{
PALAVRAS-CHAVE:
}

Intervenção Judicial; Políticas Públicas; Saúde.

\begin{abstract}
:
This current article aims to study about the judicial intervention in public policies, binding it to the understanding uttered in decisions of the Federal Supreme Court and Supreme Court of Justice, related to the fundamental social right to health, concerned to the concession of medicines not listed by SUS. As an assumption of analysis, it starts from an evaluative speech adopted in the midst of new paradigms of constitutional jurisdiction, whose protection focus must propose an alignment with logical elements, capable of promoting the rationalization of legal arguments. From this, it is sought to avoid the extrapolation of judicial activism, slithering in feasible arbitrariness of judgement in the conduction of public policies. In truth, the judicial activism must be guided by the necessity of controlling the execution of administrative goals, emphasizing the effectiveness of constitutional commands, allied to reasonableness of fruition of intended legal assets. This theoretical contributions grounds the analysis of the health case here dealt, which it is entailed the stipulation of parameters balanced by superior courts, capable of pondering between the limits of judicial intervention and the required installment of fundamental right invoked, observing the degree of administrative autonomy to be preserved. The methodology used consists in bibliographical, documental and jurisprudential research, besides the application of content analysis to give significance to the data collected.
\end{abstract}

\section{KEY WORDS:}

Judicial Intervention; Public Policies; Health.

\section{INTRODUÇÃO}

Este artigo tem por objetivo analisar os limites e possibilidades da intervenção judicial em políticas públicas, buscando alinhá-la a parâmetros que satisfaçam os objetivos fundamentais do Estado, adequando-se, ao mesmo tempo, à estrutura orgânica federativa. Para tanto, será analisado um caso emblemático, relativo à saúde, e sua resolução no âmbito do Supremo Tribunal Federal e do Superior Tribunal de Justiça. 
A discussão se inicia partindo do reporte ao constitucionalismo compromissório e dirigente enquanto precursor de um novo modelo valorativo, calcado na afirmação de um núcleo de direitos que clamava por proteção, cotejando-o como fundamento da jurisdição constitucional evocada. Nessa linha, a atividade jurisdicional ganha enfoque, na medida em que se enquadra na dimensão de busca das garantias sociais, e, por conseguinte, na invocação do cumprimento das políticas públicas previstas de forma programática no texto constitucional.

O alcance principiológico conferido ao ordenamento jurídico motivou essa escalada, a qual demanda um equilíbrio institucional entre os poderes, que se perfaz através de argumentos de racionalidade jurídica, passíveis de direcionarem o julgador à melhor interpretação constitucional, sem descaminhá-lo para os arredores de um ativismo exacerbado, culminando em possíveis arbitrariedades judiciais e na consequente articulação de um "governo de juízes".

Busca-se demonstrar que a atividade judicial em matérias afetas às políticas públicas deve ter como escopo o cumprimento da agenda política, e, neste sentido, o real controle de sua implementação na sociedade, garantindo-se a prestação efetiva dos direitos fundamentais sociais, e dissociando esta postura do mero ativismo judicial.

Nessa perspectiva, torna-se imperiosa a observância das balizas da discricionariedade administrativa, a fim de conformar a intervenção judicial aos seus limites, insculpindo-a nos entornos de uma reserva do "razoavelmente" possível, que se dirija à preservação do mínimo existencial das políticas públicas que traduzam direitos sociais prestacionais, tratando-se de conformá-las aos interesses maiores da coletividade e aos fins sociais do Estado democrático.

Na sequência, o presente estudo passa a analisar um caso empírico de intervenção judicial na política de saúde, à luz do pronunciamento do Supremo Tribunal Federal (STF) e do Superior Tribunal de Justiça (STJ), considerando a argumentação capaz de rumar e favorecer o deslinde das demandas junto às respectivas Cortes de justiça.

O caso a ser analisado trata da possibilidade de concessão de medicamentos não listados pelo Sistema Único de Saúde (SUS), bem como a sustentação de parâmetros realísticos que embasaram a solução da matéria, tomando-se como aporte as fundamentações extraídas do recurso extraordinário $n^{\circ} 566471$ e do recurso especial $n^{\circ} 1.657 .156$. 
Os métodos de pesquisa empregados no desenvolvimento deste artigo consistem em revisão bibliográfica, conduzida através de referencial teórico proposto à resolução adequada dos problemas apostos, pesquisa documental e jurisprudencial, realizada nos sítios dos tribunais superiores (STF e STJ), fazendo-se uso da análise de conteúdo para significar os dados colhidos na análise documental realizada.

\section{ENTRE A CONSTITUCIONALIZAÇÃO, O ATIVISMO JUDICIAL E A BUSCA DE UMA ARGUMENTAÇÃO RACIONAL}

A insurgência do modelo valorativo dos direitos fundamentais deu-se no bojo das novas complexidades sociais que passaram a ter expressão após um período de barbárie vivenciado durante a segunda guerra mundial. $\mathrm{O}$ mundo necessitava recriar uma legislação capaz de assegurar os direitos violados, de tal forma que o constitucionalismo democrático se expande enquanto um movimento jurídico-político de persecução dos ideais garantidores do bem-estar social (BURGOS; SALLES; VIANNA, 2006, p. 2; RAMOS NETO, 2009, p. 1).

Tornou-se necessário, portanto, agregar máxima efetividade à letra da Constituição, ressignificando-a aos moldes da jurisdição constitucional, no intuito de viabilizar a concreção dos programas sociais previstos, garantindo o usufruto do núcleo dogmático que a sustenta.

Uma nova teoria do direito, com viés principiológico, passa a fundamentar o "Welfare State”, possibilitando sua sobreposição em relação aos ideais liberalistas e aos regimes autoritários, buscando reafirmar, no cenário brasileiro, os mecanismos de consolidação da cidadania e as aspirações invocadas pela modernidade (BURGOS; SALLES; VIANNA, 2006, p. 3; TRINDADE, 2012, p. 96-97).

Alinha-se nesse horizonte a Carta Constitucional de 1988, que fixou "com força os direitos civis da cidadania, concedeu configuração institucional à democracia política e instituiu mecanismos necessários a uma gestão pública mais eficiente" (BURGOS; SALLES; VIANNA, 2006, p. 5). Nesses moldes, o texto constitucional assume uma função normativa, não mais 
visto "como uma mera 'promessa' - que, como tal, poderia ser cumprida ou não -, mas sim como um documento a ser levado a sério" (RAMOS NETO, 2009, p. 3).

Streck (2017, p. 234) aponta para o modelo transformador assumido pelo Estado, o qual se desprende da concepção liberal para voltar-se à promoção dos direitos sociais, tendo como um dos objetivos federativos a erradicação da pobreza, da marginalização e a redução das desigualdades sociais e regionais ${ }^{4}$. A implementação das políticas públicas torna-se, portanto, imperiosa, viabilizando a patente atuação da jurisdição constitucional na efetivação de direitos fundamentais prestacionais.

Essa “invasão do Direito sobre o social” (BURGOS; SALLES; VIANNA, 2006, p. 3), propiciou a severa atuação do Judiciário enquanto condutor de questões públicas, reafirmando garantias tendentes a esculpir o modelo valorativo almejado, prestigiando a efetividade da Constituição.

Para Ramos Neto (2009, p. 2), vive-se um momento de "euforia constitucional", incrementada pela "era dos princípios", que trouxe consigo a fluidez interpretativa, tornando "hercúlea a tarefa de definição do conteúdo da norma regente do caso concreto, especialmente à luz de uma necessária racionalidade argumentativa”.

A interpretação constitucional, com vistas a garantir os direitos sociais positivados, passa a enfrentar o dilema que se volta à definição dos limites da discricionariedade judicial, onde se inicia e onde deve atingir o seu termo, buscando evitar decisões respaldadas em criações jurídicas arbitrárias, carentes de fundamento lógico, traduzidas no que Streck (2017, p. 229230) articulou enquanto uma "Jurisprudência de Valores". Esse conceito revela a subjetividade do julgador, ancorada na expressão dos seus valores, cujo texto normativo encobre a faceta criativa.

Não se busca, assim, defender a discricionariedade e o relativismo das decisões judiciais, mas correlacionar uma postura ativista a um fundamento de validade, através da ponderação de princípios, tomando-se como subsídio a teoria da argumentação jurídica.

\footnotetext{
${ }^{4}$ Art. $3^{\circ}$ Constituem objetivos fundamentais da República Federativa do Brasil: [...]

III - erradicar a pobreza e a marginalização e reduzir as desigualdades sociais e regionais.
} 
É nessa perspectiva que se diferencia o mero ativismo judicial de um constitucionalismo compromissório e dirigente, utilizando-se como bússola hermenêutica os parâmetros de uma jurisdição constitucional mais efetiva, voltada à concretização da democracia e da cidadania. Ao contrário, quando o Estado deixa de elaborar suas políticas públicas para atender aos comandos judiciais, tal atitude revela o desprestígio e consequente enfraquecimento da cidadania (STRECK, 2017, p. 230-231), da legitimidade democrática e da separação harmônica entre os poderes republicanos.

Nesse sentido, a intervenção judicial nas matérias afetas à administração pública deve partir de um discurso prévio de fundamentação, o qual servirá para indicar os limites que definem um argumento de princípio e um simples argumento de política (STRECK, 2017, p. 232), mormente quando o juiz se esbarra com uma espécie de "caso difícil” (DWORKIN, 2011, p. 129), cuja interpretação ultrapassa "as experiências exegético-subsuntivas e as tentativas de controlar os sentidos por meio de operações lógico-analíticas" (STRECK, 2017, p. 329). Esse modelo hermenêutico eleva a técnica da argumentação, "a partir da construção de racionalidades comunicativas, estabelecendo previamente modos de operar diante da indeterminabilidade do Direito" (STRECK, 2017, p. 329).

Essa efervescência jurisdicional encontra ainda guarida nas chamadas "zonas cinzentas que surgem entre a legislação e a aplicação do direito" (STRECK, 2017, p. 235), justificando a necessidade de amparo aos direitos sociais, para que sua previsão não se torne inócua na narrativa constitucional e sua eficácia possa ser sentida no meio social.

Desse modo, Streck (2017, p. 239-240) propõe a delimitação de elementos racionais a serem observados, a fim de embasar e validar a intervenção judicial em matéria administrativa, com foco na propagação da jurisdição constitucional mais próxima do cidadão:

Percebe-se, assim, que a atribuição de sentido do que pode (ou deve) receber a chancela da jurisdição constitucional carece (ainda), para utilizar os próprios pressupostos habermasianos, de um discurso de fundamentação prévio (discursos de validade), do qual se possa extrair os limites e as condições de possibilidade sobre a oportunidade (ou não) de lançar mão do direito constitucional por meio de um controle judicial de constitucionalidade apto para estabelecer, entre outras coisas: a) "a clareza do direito e para a manutenção de uma ordem jurídica coerente"; b) a possibilidade de intervenção nos casos de "zonas cinzentas que surgem entre legislação e aplicação do direito"; c) quais as situações permissivas de "configuração criativa" da jurisdição constitucional (grifo do autor). 


\section{A INTERVENÇÃO JUDICIAL NA CONDUÇÃO DAS POLÍTICAS PÚBLICAS: UM GOVERNO DE JUÍZES?}

A Constituição dirigente de 1988, em seu texto aberto a princípios e valores, outorgou ao Estado a competência para a elaboração e implementação de políticas públicas em diversas áreas afetas aos direitos fundamentais sociais, estabelecendo programas específicos, cuja intervenção na vida dos destinatários passa a depender de medidas efetivas provindas dos âmbitos legislativo e executivo. Assim, para o alcance dos objetivos fundamentais da República Federativa do Brasil", o Estado necessita organizar-se no "facere" e "praestare", transformando-se de Estado social de direito, para Estado democrático de direito (GRINOVER, 2010, p. 12).

Buscando aferir a natureza das políticas públicas, no intuito de dissociá-la das teorias que tratam da revisão judicial dos atos administrativos, Appio (2004, p. 217) afirma que o conceito de políticas públicas pode ser desenvolvido enquanto "instrumentos de execução de programas políticos baseados na intervenção estatal na sociedade com a finalidade de assegurar igualdade de oportunidades aos cidadãos, tendo por escopo assegurar as condições materiais de uma existência digna a todos os cidadãos". Para Mânica (2008, p. 90), “as políticas públicas podem se encontrar consubstanciadas em leis ou atos normativos, mas com eles não se confundem, pois decorrem do conjunto de atos e/ou de normas que implementam valores e objetivos albergados pelo ordenamento jurídico”.

Com base nessa compreensão, a partir do momento em que os entes responsáveis pela condução da norma constitucional deixam de cumpri-la, de modo efetivo e adequado às exigências populares, nasce uma predisposição de avanço do poder Judiciário, motivada, em larga escala, pela crescente mobilização dos cidadãos em prol do cumprimento da agenda política (BRANDÃO, 2013, p. 192), com enfoque para a promoção de uma concepção

\footnotetext{
${ }^{5}$ Art. $3^{\circ}$ Constituem objetivos fundamentais da República Federativa do Brasil:

I - construir uma sociedade livre, justa e solidária;

II - garantir o desenvolvimento nacional;

III - erradicar a pobreza e a marginalização e reduzir as desigualdades sociais e regionais;

IV - promover o bem de todos, sem preconceitos de origem, raça, sexo, cor, idade e quaisquer outras formas de discriminação.
} 
contemporânea de democracia, visibilizada através da ampliação do universo de pessoas e entes responsáveis pela efetivação das políticas públicas (APPIO, 2004, p. 216).

Para Appio (2012, p. 70), a Constituição Federal de 1988, ao inserir um sistema de aplicação principiológica de suas normas, notadamente amplia o poder de intervenção judicial em políticas públicas, nas áreas social e econômica. Contudo, este poder não garante a governabilidade judicial, uma vez que não confere ao magistrado a prerrogativa de eleger a política pública que julgue mais apropriada ao caso concreto, limitando-se ao controle da execução perante a previsão constitucional.

Nessa linha, a justificativa em torno de uma hermenêutica constitucional adequada pode resvalar verdadeira aventura política, tendente a provocar a erosão dos preceitos constitucionais. A busca de limites ao exercício da jurisdição deve revelar-se como postulado da democracia, mantendo-se o equilíbrio e coesão entre os poderes, de modo que um governo de juízes significaria a típica ascensão de um governo aristocrático (APPIO, 2012, p. 71), cuja concentração de forças não traduz a materialidade constitucional que se almeja.

Esse desequilíbrio, além de incompatível com o sistema representativo constitucional, provoca tensão institucional entre as esferas do poder, além de levar a uma "crise de governabilidade" (APPIO, 2004, p. 242). "Esta postura conduz [ainda] a uma superposição de esferas, critérios e lógicas decisórias, a uma erosão de valores precípuos de cada um dos Poderes da República e a uma sobrecarga no policy making do país” (APPIO, 2004, p. 242).

Em verdade, o que se sustenta é que a Carta Magna, ao estabelecer uma rede de proteção em matéria de políticas públicas e direitos sociais, não autorizou a ingerência do Judiciário na definição do conteúdo das matérias, tampouco na definição do momento de sua efetiva implementação, restringindo-o à função fiscalizatória que lhe é imposta enquanto defensor da jurisdição constitucional ${ }^{6}$. Neste caso, restaria maculada a legitimidade

\footnotetext{
${ }^{6}$ Segundo Appio (2004, p. 216-217), há três momentos distinguíveis acerca do controle judicial de políticas públicas: na sua formulação, execução ou avaliação. Esse controle pode ser presenciado, portanto, em caráter preventivo, concomitante e sucessivo à implementação dos programas sociais e econômicos. Assim, "a avaliação judicial das políticas públicas não se apresenta como novidade no contexto brasileiro, já que se faz a partir do controle de legalidade e legitimidade atos administrativos [sic], especialmente através da aplicação da Lei de Improbidade administrativa (Lei 8.429/92), bem como através dos instrumentos de repressão penal. Ademais, existem instrumentos correlatos ao controle exercido pelo Congresso Nacional com o auxílio dos Tribunais de Contas, visando assegurar a própria credibilidade das políticas públicas a serem implementadas. Contudo, a participação do Poder Judiciário no processo de formulação e execução das políticas públicas se apresenta como
} 
democrática ao conferir a um poder de caráter contramajoritário ${ }^{7}$ a responsabilidade solidária por ações sociais típicas dos poderes Executivo e Legislativo, fundadas em suas discricionariedades.

Ocorre então que, a pretexto de utilizar seu poder controlador, o Judiciário acaba adotando verdadeira postura administrativa, alimentando os discursos que remetem a um possível "governo de juízes". "A intervenção judicial deixa de ter natureza exclusivamente invalidatória, passando a assumir uma função substitutiva, com o que se pode falar em atividade administrativa do Poder Judiciário" (APPIO, 2012, p. 138).

Diferentemente, quando o poder Judiciário atua verificando o efetivo cumprimento das metas da Administração, em consonância ao princípio constitucional da eficiência, age em um processo de racionalização da aplicação do direito ${ }^{8}$, dando ênfase à concretização dos direitos fundamentais. Estimula-se assim o debate e preserva-se o regime democrático (MANCUSO, 2011, p. 39).

Segundo Canela Júnior (apud GRINOVER, 2010, p. 14), tomando-se o juiz como coautor de políticas públicas, "fica claro que sempre que os demais poderes comprometerem a integridade e a eficácia dos fins do Estado - incluindo as dos direitos fundamentais, individuais ou coletivos -, o Poder Judiciário deve atuar na sua função de controle".

É de se perceber que a atuação judicial passa a se legitimar perante os espaços deixados "em branco" pelas outras esferas do poder, notadamente o Legislativo e o Executivo em matéria de políticas públicas. Segundo Appio (2004, p. 239), “a proposição de transferência ao Poder

fenômeno absolutamente inédito, pois implica a substituição de um ato de vontade dos governos eleitos por um ato de vontade de juízes não-eleitos".

${ }^{7}$ Mancuso (2011, p. 74) aponta para este caráter com a expressão "dificuldade contramajoritária", cunhada pela doutrina constitucional e "consistente nisso que a legitimidade da intervenção judicial é de base técnica (aprovação em concurso público ou acesso pelo quinto constitucional), e se expressa numa atuação a posteriori (vedação da justiça de ofício), ao passo que a Administração Pública atua (para o bem ou para o mal, errando ou acertando) mas de todo modo legitimada pelo mandato popular concedido aos governantes, tratando-se, pois, de uma legitimidade de índole primária, já que o Poder, originariamente, pertence ao povo (CF/1988, parágrafo único do art. $1^{\circ}$ ). Aquela dificuldade consiste, então, em se encontrar o modo, os limites e os parâmetros pelos quais os juízes, posto não escolhidos pela população, venham a sindicar atos, condutas, escolhas e programas encetados pelas instâncias políticas" (grifo do autor).

${ }^{8}$ Conforme terminologia empregada por Eduardo Appio (2008, p. 50), ao propor o dilema: "o Direito está fundado numa opção irracional do juiz, baseada num voluntarismo não confessado ou é possível racionalizar a aplicação do Direito e, portanto, da Constituição?" 
Judiciário das funções destinadas aos demais Poderes da República é sintomática de uma crise de confiança no atual sistema”.

É problemático, portanto, falar-se em excesso de ativismo quando se está diante de uma conduta primária leniente, visto que se estaria tomando a consequência como a causa do imbróglio, desconfigurando o nexo e desajustando ainda mais o sistema de garantias fundamentais ${ }^{9}$. Trata-se de assegurar a diferença delimitada por Streck (2017, p. 230) entre constitucionalismo compromissório (e dirigente) e ativismo judicial ${ }^{10}$.

Santos (2011, p. 24) acredita que "muita da litigação que hoje chega aos tribunais devese ao desmantelamento do Estado social (direito laboral, previdência social, educação, saúde, etc.)". Nesse ponto, defende a necessidade de o Judiciário posicionar-se, em grande medida, na condição de ultima ratio para a consecução das garantias constitucionais:

É evidente que o sistema judicial não pode resolver todos os problemas causados pelas múltiplas injustiças. Mas, tem que assumir a sua quota-parte de responsabilidade na resolução. O sistema judicial está, hoje, colocado perante o seguinte dilema. Se não assumir a quota-parte da sua responsabilidade, continuará a ser independente de um ponto de vista corporativo, mas será cada vez mais irrelevante tanto social como politicamente (SANTOS, 2011, p. 40, grifo nosso).

\footnotetext{
${ }^{9}$ Exemplo emblemático desponta da análise do Recurso extraordinário $\mathrm{n}^{\mathrm{o}} 592.581$, ocorrido na data de 13 de agosto de 2015, onde o Plenário do Supremo Tribunal Federal (STF) decidiu, por unanimidade e sob repercussão geral, que o Judiciário, ao impor à Administração Pública a oferta de obras de melhorias emergenciais em estabelecimentos prisionais, visando cumprir às determinações constitucionais assecuratórias da dignidade humana dos detentos, não extrapola os limites de sua atuação jurisdicional. Para o ministro relator Ricardo Lewandowski, o caso em tela evidencia flagrante ofensa aos direitos fundamentais, já que, no atual Estado democrático de direito, considerada a prisão como exceção, devem ser ofertadas ao preso as garantias necessárias para que exerça seu múnus com dignidade, possibilitando a futura ressocialização. Por essas razões, acreditou o colegiado que não se estava diante da implementação de uma política pública pelo Judiciário, em afronta ao princípio da separação dos poderes e ao argumento da reserva possível, já que a atuação provinha de patente omissão estatal, apta a afastar a hipótese de excesso de ativismo judicial. O limite foi claramente definido pelo ministro Lewandowski, esclarecendo que a simples invocação de ameaça a direitos fundamentais não embasa a pretensão jurídica, de modo que os juízes devem se ater ao desenho constitucional da repartição dos poderes, sem a pretensão de fazer de seu ofício um governo. Deve, portanto, restar clara a retração inconstitucional da autoridade estatal e as incontestáveis consequências gravosas aos jurisdicionados: "Nesse ponto, cumpre esclarecer que, não se está a afirmar que é dado ao Judiciário intervir, de ofício, em todas as situações em que direitos fundamentais se vejam em perigo. Dito de outro modo, não cabe aos magistrados agir sem que haja adequada provocação ou fundados apenas em um juízo puramente discricionário, transmudando-se em verdadeiros administradores públicos. Aos juízes só é lícito intervir naquelas situações em que se evidencie um 'não fazer' comissivo ou omissivo por parte das autoridades estatais que coloque em risco, de maneira grave e iminente, os direitos dos jurisdicionados. Em nenhum momento aqui se afirma que é lícito ao Judiciário implementar políticas públicas de forma ampla, muito menos que lhe compete 'impor sua própria convicção política, quando há várias possíveis e a maioria escolheu uma determinada"".

${ }^{10}$ Cf. apresentado no capítulo 2.
} 
Partindo dessa compreensão, Appio (2004, p. 234) explica que a intervenção judicial em políticas públicas torna-se compatível ao regime constitucional democrático, quando inexistir reserva absoluta de lei ou de discricionariedade administrativa, e "desde que observados os mecanismos de comunicação entre a instância judicial e a sociedade, através das instâncias de democracia participativa", visando o pronunciamento efetivo acerca das aflições sociais que pugnem pela prestação dos respectivos direitos, e garantidos os parâmetros da jurisdição constitucional, afastando-se de um mero decisionismo, fruto de preferências jurídicas.

\subsection{A inoponibilidade da reserva do possível para a garantia do mínimo existencial}

A divisão orgânica dos poderes pressupõe o Executivo como um poder capaz de determinar os recursos a serem destinados aos programas sociais de matriz constitucional. Quando se fala em "reserva do possível" ", a análise apriorística que é feita se reporta à limitação do prévio empenho do recurso orçamentário disponível, para fazer face às escolhas governamentais das políticas públicas que serão implementadas, tendo como escopo a realização dos direitos sociais prestacionais ${ }^{12}$.

Nesse ponto, Appio (2008, p. 118-119; 2012, p. 175) afirma que a inoponibilidade da reserva do possível em face do Judiciário só pode ser operada em relação a políticas públicas já implementadas pelo governo, pois neste caso eleva-se o dever estatal de analisar previamente

${ }^{11}$ Conforme apontado por Mânica (2008, p. 99), a cláusula da reserva do possível foi inicialmente aventada em
julgamento oriundo do Tribunal Constitucional alemão, em decisão conhecida como "Numerus Clausus": "No
caso, a Corte alemã analisou demanda judicial proposta por estudantes que não haviam sido admitidos em escolas
de medicina de Hamburgo e Munique em face da política de limitação do número de vagas em cursos superiores
adotada pela Alemanha em 1960 . A pretensão foi fundamentada no artigo 12 da Lei Fundamental daquele Estado,
segundo a qual "todos os alemães têm direito a escolher livremente sua profissão, local de trabalho e seu centro
de formaçãa". Ao decidir a questão o Tribunal Constitucional entendeu que o direito à prestação positiva - no
caso aumento do número de vagas na universidade - encontra-se sujeito à reserva do possível, no sentido daquilo
que o indivíduo pode esperar; de maneira racional, da sociedade. Ou seja, a argumentação adotada refere-se à
razoabilidade da pretensão" (grifos do autor).
${ }^{12}$ Sarlet (2012, p. 285-286) distingue a "relevância econômica" existente entre os direitos sociais prestacionais,
que requerem do Estado uma conduta positiva, e os direitos de defesa, atinentes a uma conduta omissiva. Para o
autor, muito embora os direitos fundamentais, lato sensu, serem essencialmente direitos positivos, e,
consequentemente, possuírem sempre alguma relevância econômica - ainda que, no caso dos direitos de liberdade
e de defesa, esses custos estejam voltados à alocação de recursos materiais e humanos -, compreende-se, em
princípio, que há uma certa "neutralidade econômico-financeira" quando esta abordagem se volta aos direitos
negativos, "na medida em que o objeto de sua proteção como direitos subjetivos (vida, intimidade, liberdades etc.)
pode ser assegurado juridicamente, independentemente das circunstâncias econômicas" (SARLET, 2012, p. 285). 
a suficiência dos recursos financeiros passíveis à cobertura da despesa, o que não sucede em relação aos programas ainda não formulados. No primeiro caso, busca-se evitar o populismo midiático e eleitoreiro, impedindo que a inexecução de uma política pública de notável grandeza se transforme em frustração popular, sob a égide da reserva do possível.

Assim sendo, “a implementação das políticas públicas de natureza social é, portanto, um ato de grande responsabilidade política, razão pela qual não admite a outorga ilusória de direitos sociais, condicionados à disponibilidade do orçamento público" (APPIO, 2012, p. 175).

Esse entendimento faz predominar interpretação conducente a uma "teoria da reserva do financeiramente possível", voltada exclusivamente à existência e disponibilidade de recursos financeiros no orçamento público, sem se atentar para a efetiva razoabilidade da pretensão que envolva a satisfação de um direito fundamental social (MÂNICA, 2008, p. 100), a qual se mede por meio da aplicação conjunta do princípio da proporcionalidade ${ }^{13}$, que significa, "em última análise, a busca do justo equilíbrio entre os meios empregados e os fins a serem alcançados" (GRINOVER, 2010, p. 19). A observância à efetiva necessidade, adequação e proporcionalidade restrita dos fins perseguidos evita a ocorrência de intervenções judiciais desmedidas em matéria de políticas públicas, passíveis de desembocar em causas de arbitrariedades cometidas por magistrados.

Isso significa que pretensões deduzidas perante o Poder Judiciário deverão ser analisadas mediante a ponderação de bens, com base no critério da proporcionalidade. [...] Assim, o custo direto envolvido para a efetivação de um direito fundamental não pode servir como óbice intransponível para sua efetivação, mas deve ser levado em conta no processo de ponderação de bens. Além disso, deve participar do processo de ponderação a natureza de providência judicial almejada, em especial no que se refere a sua necessidade, adequação e proporcionalidade específica para a proteção do direito fundamental invocado. (MÂNICA, 2008, p. 103-104, grifo nosso)

O objetivo da utilização do critério da ponderação aqui analisado reflete-se enquanto um parâmetro de atuação judicial voltado à plena realização dos preceitos da jurisdição

\footnotetext{
${ }^{13}$ Segundo Canotilho (apud GRINOVER, 2010, p. 19), o princípio da proporcionalidade em sentido amplo compõe-se dos seguintes subprincípios: “a) princípio da conformidade ou adequação de meios (Geeignetheit), que impõe que a medida seja adequada ao fim; b) princípio da exigibilidade ou da necessidade (Erforderlichkeit) ou princípio da necessidade ou da menor ingerência possivel, que impõe a ideia de menor desvantagem possível ao cidadão; c) princípio da proporcionalidade em sentido restrito (Verhältnismässigkeit) importando na justa medida entre os meios e o fim" (grifos da autora).
} 
constitucional, aliando-se à perspectiva de que a administração pública deve guiar-se de acordo com os interesses sociais supremos e sua conformação constitucional. Neste sentido:

\begin{abstract}
Conclui-se daí, com relação à intervenção do Judiciário nas políticas públicas, que por meio da utilização de regras de proporcionalidade e razoabilidade, o juiz analisará a situação em concreto e dirá se o administrador público ou o responsável pelo ato guerreado pautou sua conduta de acordo com os interesses maiores do indivíduo ou da coletividade, estabelecidos pela Constituição e nas leis [grifo nosso]. E assim estará apreciando, pelo lado do autor, a razoabilidade da pretensão individual/social deduzida em face do Poder Público. E, por parte do Poder Público, a escolha do agente público deve ter sido desarrazoada (GRINOVER, 2010, p. 23, grifos da autora).
\end{abstract}

Com efeito, busca-se afastar o argumento da reserva do "financeiramente possível" quando confrontado com direitos fundamentais que se extraem do mínimo existencial, concebido como o núcleo "duro" e essencial para a satisfação da dignidade humana (GRINOVER, 2010, p. 18; MANCUSO, 2011, p. 89; SARLET, 2012, p. 411), funcionando assim enquanto um divisor de águas para o exercício do poder jurisdicional, ou uma espécie de “filtro", apto a conduzir ao exame concreto da proporcionalidade (SARLET, 2012, p. 412). "É esse núcleo central, esse mínimo existencial que, uma vez descumprido, justifica a intervenção do Judiciário nas políticas públicas, para corrigir seus rumos ou implementá-las” (GRINOVER, 2010, p. 18).

Assim, segundo Mancuso (2011, p. 89),

um critério bastante consistente para fixação dos limites da intervenção judicial no controle das políticas públicas é oferecido por Kazuo Watanabe: começa por afirmar que "em relação aos direitos fundamentais sociais que estejam referidos ao núcleo duro do princípio da dignidade humana e por isso integram o conceito de 'mínimo existencial', é inoponível a cláusula da 'reserva do possível”" (...) "Os demais direitos fundamentais sociais, que não correspondem ao núcleo básico da dignidade humana e por isso não são qualificáveis como asseguradores do 'mínimo existencial', e tampouco estejam consagrados em normas constitucionais de 'densidade suficiente', não desfrutam da tutelabilidade jurisdicional sem a prévia ponderação do Legislativo ou do Executivo, por meio de definição de política pública específica. Em relação a eles deve ser resguardado o debate democrático e preservado o pluralismo político, no âmbito do Legislativo e do Executivo (grifo do autor).

Partindo da exposição até aqui apresentada, e considerando o direito à saúde como indicador primário de política afeta à dignidade humana, refletor do mínimo existencial, e perfeitamente alocado enquanto direito fundamental social ${ }^{14}$, passa-se à análise de caso

\footnotetext{
${ }^{14}$ Art. $6^{\circ}$ São direitos sociais a educação, a saúde, a alimentação, o trabalho, a moradia, o transporte, o lazer, a segurança, a previdência social, a proteção à maternidade e à infância, a assistência aos desamparados, na forma desta Constituição.
} 
paradigmático enfrentado pelo Supremo Tribunal Federal e pelo Superior Tribunal de Justiça, onde a intervenção judicial ganha enfoque, balizada pelas diretrizes então estabelecidas.

\section{ANALISANDO UM CASO EMBLEMÁTICO DE INTERVENÇÃO JUDICIAL NA POLÍTICA DE SAÚDE: A CONCESSÃO DE MEDICAMENTOS NÃO LISTADOS PELO SUS}

Em 15 de novembro de 2007, o Supremo Tribunal Federal (STF) decidiu pela repercussão geral do recurso extraordinário $n^{\circ}$ 566471, interposto pelo Estado do Rio Grande do Norte, cujo tribunal de origem negou acolhida ao pedido formulado em sede de apelação ${ }^{15}$.

O caso, pendente de julgamento final, trata do fornecimento de medicamento de alto custo não inserido no programa de dispensação do Sistema Único de Saúde (SUS), tendo o Estado alegado, em síntese: o comprometimento do orçamento público ao destinar verbas de programas sociais para o custeio de tratamento individual; a ofensa à reserva do possível e à legalidade orçamentária; a ausência de base constitucional, tendo em vista o caráter programático das normas relativas à saúde, e, ainda, a falta de comprovação da eficácia dos medicamentos, uma vez que, em muitos casos, utilizam-se fármacos não para o reparo da saúde, mas sim para o prolongamento precário da vida por mais algum tempo ${ }^{16}$.

\footnotetext{
15 Constitucional. Ação de obrigação de fazer. Tutela antecipada. Preliminar de nulidade da sentença. Litisconsórcio passivo necessário. Transferência para o mérito. Fornecimento de medicamento de alto custo. Recusa do Estado em fornecê-lo. Impossibilidade. Afronta a direitos assegurados pela Constituição Federal. Obrigação do Estado apelante em promover o fornecimento de medicamento imprescindível ao tratamento de saúde da apelada. Manutenção da sentença de $1^{\circ}$ grau. Precedentes desta Egrégia Corte. Recurso conhecido e improvido. Disponível em: < http://www.stf.jus.br/arquivo/cms/noticiaNoticiaStf/anexo/RE566471.pdf>. Acesso em: 20 jun. 2019.

${ }_{16}$ Mancuso (2011, p. 99) cita notícia do Jornal O estado de São Paulo, de 28/11/2010, cad. A-3, acerca dos problemas da intervenção judicial em políticas de saúde, referentes aos pedidos de medicamentos: "[...] os remédios pedidos por promotores e defensores públicos em nome de pacientes são caros e o mercado dispõe de similares mais baratos. O Ministério da Saúde também alega que vários medicamentos cuja distribuição tem sido imposta por liminares teriam duvidosa eficácia terapêutica. Para as Secretarias Municipais de Saúde, as ações que pedem medicamentos e atendimento médico fora das listas e procedimentos médicos do SUS estariam comprometendo o planejamento e até as finanças dos Estados e Municípios. Só em São Paulo, a Secretaria de Saúde gasta mais de R $\$ 300$ milhões por ano para cumprir liminares - o valor é equivalente ao custo de construção de seis hospitais de porte médio".
} 
O Ministro relator Marco Aurélio, defendendo o viés fundamental do direito à saúde e albergando-o ao conjunto do mínimo existencial, dispôs em seu voto acerca do compromisso do Estado com suas funções primárias. Para o relator, não cabe ao Judiciário imiscuir-se nos aspectos objetivos das políticas públicas de saúde, devendo amparar-se na fiscalização da real efetivação dessas políticas aos que dela necessitem, alinhando-as à perspectiva de fundamentalidade do direito postulado. Segundo trecho de seu voto:

\begin{abstract}
A saúde, nela englobado o acesso a medicamentos, constitui bem vinculado à dignidade do homem. É verdade que o desenvolvimento da dimensão objetiva do direito à saúde deve ficar a cargo de políticas públicas. Todavia, os traços de fundamentalidade, inalienabilidade, essencialidade e plena judicialização desses direitos estarão sempre presentes na dimensão do mínimo existencial. $\mathrm{O}$ direito à saúde como direito ao mínimo existencial é direito fundamental (p. 5, grifo nosso). [...] Sabe-se que há, no País, a Política Nacional de Medicamentos, com a elaboração de listas daqueles a serem distribuídos aos que necessitem, destacando-se o Programa de Medicamentos de Dispensação em Caráter Excepcional, referente aos remédios de alto custo ou excepcionais. Espera-se que essas políticas cheguem, progressivamente, à distribuição universal e ao uso racional dos medicamentos. Entretanto, não se discute o controle jurisdicional do mérito amplo dessas políticas, e sim a tutela judicial de situações especiais, quando não alcançadas por essas políticas. Não cabe ao Poder Judiciário formular políticas públicas, mas pode e deve corrigir injustiças concretas (p. 7, grifo nosso).
\end{abstract}

Ao final, o Ministro propôs a seguinte tese ${ }^{17}$, a fim de orientar a Corte com premissas para o julgamento do caso:

\begin{abstract}
o reconhecimento do direito individual ao fornecimento, pelo Estado, de medicamento de alto custo, não incluído em Política Nacional de Medicamentos ou em Programa de Medicamentos de Dispensação em Caráter Excepcional, depende da comprovação da imprescindibilidade - adequação e necessidade -, da impossibilidade de substituição do fármaco e da incapacidade financeira do enfermo e dos membros da família solidária, respeitadas as disposições sobre alimentos dos artigos 1.694 a 1.710 do Código Civil (grifos nossos).
\end{abstract}

Subsequentemente, na data de 5 de março de 2009, o então presidente do STF, Ministro Gilmar Mendes, convocou audiência pública para discussão de parâmetros acerca da política judiciária relativa à saúde pública no país. A audiência ocorreu entre as datas de 27 a 29 de abril e 4, 6 e 7 de maio, e contou com 50 (cinquenta) especialistas, entre professores, médicos, técnicos de saúde, gestores e usuários do SUS, além dos profissionais da área

\footnotetext{
${ }^{17}$ Segundo Mello (2016, p. 278), “a definição da tese [...], se aproxima da formulação de uma súmula, já que, a partir da decisão concreta, o Tribunal elabora uma norma abstrata que corresponde ao verbete vinculante para as instâncias inferiores. Parece remanescer, contudo, um maior espaço argumentativo no caso da repercussão geral, já que, na aplicação da tese, as instâncias vinculadas poderão revisitar o acórdão que a produziu e reinterpretá-la, à luz de seus fatos e fundamentos, e, ainda, à luz das decisões posteriores que impactem sobre seu sentido. De fato, na repercussão geral, não se define um verbete, em termos canônicos, como ocorre com as súmulas vinculantes, cujo teor só pode ser alterado por meio de procedimento formal junto ao próprio STF".
} 
jurídica $^{18}$, visando promover o deslinde de questões técnicas, científicas, administrativas, políticas e econômicas, afetas às lides judiciais que tratam do direito à saúde ${ }^{19}{ }^{20}$ (BALESTRA NETO, 2015, p. 91).

O Superior Tribunal de Justiça, por sua vez, julgou em 12 de setembro de 2018 os embargos de declaração no recurso especial n 1.657.156, o qual foi decidido sob a sistemática dos recursos repetitivos ${ }^{21}$.

Tratava-se de paciente portadora de glaucoma crônico bilateral (CID 440.1), necessitando de tratamento por meio de medicamentos específicos, não incorporados em atos normativos do SUS, mas devidamente prescritos por médico do sistema. A imprescindibilidade da medicação, assim como a ausência de condições financeiras da autora para arcar com os custos do tratamento, foram reconhecidos pelo tribunal de origem e corroborados no julgamento do recurso especial.

Ao final do julgamento dos embargos propostos pelo Estado do Rio de Janeiro, pela União e pela parte autora, a Corte máxima, por meio do Ministro relator Benedito Gonçalves, fixou a seguinte tese:

A tese fixada no julgamento repetitivo passa a ser: A concessão dos medicamentos não incorporados em atos normativos do SUS exige a presença cumulativa dos seguintes requisitos: i) Comprovação, por meio de laudo médico fundamentado e

18 Conforme notícia publicada no portal: http://www.stf.jus.br/portal/cms/verTexto.asp?servico=processoAudienciaPublicaSaude>. Acesso em: 20 jun. 2019.

${ }^{19}$ Segundo Balestra Neto (2015, p. 91), o STF deliberou na audiência a obrigação do Estado de: “(a) fornecer prestação de saúde prescrita por médico não pertencente ao quadro do Sistema Único de Saúde (SUS), (b) custear prestações de saúde não abrangidas pelas políticas públicas existentes, (c) disponibilizar medicamentos e tratamentos experimentais não registrados na Agência Nacional de Vigilância Sanitária (Anvisa) ou não aconselhados nos protocolos clínicos do SUS e (d) fornecer medicamento não licitado e não previsto nas listas do SUS".

${ }^{20}$ Com base nos parâmetros definidos na audiência pública, o Conselho Nacional de Justiça, em 30 de março de 2010, editou a Recomendação n $31 / 2010$, na qual sugere aos Tribunais a adoção de uma série de medidas, visando subsidiá-los na solução das demandas que envolvam o direito à saúde. Dentre as recomendações, destaca-se: a celebração de convênios, composto por médicos e farmacêuticos, a fim de disponibilizar apoio técnico para a formação de juízo de valor em questões clínicas; a instrução das ações com relatórios médicos que descrevam a doença, contendo prescrição de medicamentos, produtos, próteses, órteses, e insumos em geral, com a posologia exata, além da promoção de seminários na área da saúde, propiciando maior entrosamento na matéria. (Disponível em: < http://www.cnj.jus.br/files/atos_administrativos/recomendao-n31-30-03-2010-presidncia.pdf >. Acesso em: 20 jun. 2019).

${ }_{21}$ Disponível em: < https://jurisprudencia.s3.amazonaws.com/STJ/attachments/STJ_EDCLRESP_1657156_da144.pdf?Signature=segNXXx2vQWZd4JOmkkS1nzIAxw\%3D\&Expires=1562274851\&AW SAccessKeyId=AKIARMMD5JEAO765VPOG\&response-content-type=application/pdf\&x-amz-meta-md5hash=f3b17014df0bda580856f6c578d4048c>. Acesso em: 20 jun. 2019. 
circunstanciado expedido por médico que assiste o paciente, da imprescindibilidade ou necessidade do medicamento, assim como da ineficácia, para o tratamento da moléstia, dos fármacos fornecidos pelo SUS; ii) incapacidade financeira de arcar com o custo do medicamento prescrito; iii) existência de registro do medicamento na ANVISA, observados os usos autorizados pela agência [...] (p. 3, grifo nosso).

O entendimento que passou a vigorar é no sentido de que o laudo médico não vincula o julgador, ao mesmo tempo em que não cabe a este definir os elementos que deverão constar no referido documento técnico. Em seu âmbito de competência, caberá avaliar o laudo e verificar se as informações nele constantes são suficientes ao seu convencimento, no que tange à imprescindibilidade do medicamento pedido e à ineficácia daquele fornecido pelo SUS ${ }^{22}$.

Nota-se, na exposição do tema analisado, que as Cortes têm ponderado, buscando estabelecer parâmetros capazes de subsidiar uma argumentação racional em torno da matéria. Dessa forma, o fundamento do conteúdo do mínimo existencial, prescrito como supedâneo a amparar decisões voltadas à defesa genérica da dignidade humana, passa a ser analisado de forma mais diligente e criteriosa, a fim de se promover uma racionalização e justeza na prestação jurisdicional, cujo objetivo não se reporta à limitação da oferta do direito fundamental à saúde - em que pese o argumento de seu conteúdo constitucional programático -, mas à sua viabilização consoante os critérios da razoabilidade, proporcionalidade, necessidade e adequação ${ }^{23}$. "A solução jurídica dos casos, então, não se restringe tão somente à discussões

${ }^{22}$ No mesmo sentido: STJ - REsp. 1.682.973-RJ, Rel. Min. OG Fernandes. DJ: 05/06/2018. DJe: 11/06/2018; STJ - REsp. 1650704-PE, Rel, Min. Herman Benjamin. DJ: 25/04/2017. DJe: 05/05/2017.

${ }^{23} \mathrm{Na}$ fronteira de permissão à sindicabilidade judicial em matéria de políticas públicas afetas à saúde, Streck (2017, p. 237-238) traz exemplo que traduz a complexidade na verificação de elementos norteadores de concessões pontuais, bem como a necessidade do juiz de verificar a sua ausência ou insuficiência, a fim de fundamentar uma argumentação racional. Assim, a simples alegação da gravidade da doença e do dano irreparável advindo da falta do tratamento pugnado não se mostram suficientemente aptos a embasar uma pretensão desse jaez: "Numa palavra, veja-se a enorme dificuldade representada pela aferição da fronteira entre o que pode ser considerado ativismo (essa palavra será sempre problemática) e o que é efetivamente uma decisão sem esse epíteto. Com efeito, na Ação Civil Pública n. 70010810844 (rel. Des. Rogério Gesta Leal), foi deferido, judicialmente, direito a transporte gratuito a todos os idosos de determinada cidade, com base no art. $230, \S 2^{\circ}$. Já no Agravo de Instrumento $\mathrm{n}$. 70013968771, também da lavra de Gesta Leal, adepto explícito das teses habermasianas, sob fundamento similar, a decisão trilhou caminho inverso, cassando a tutela antecipada concedida em primeiro grau, que obrigava a municipalidade a fornecer, meio a meio com o Estado do Rio Grande do Sul, remédio de uso diário, em face de determinada pessoa estar acometida de Doença Pulmonar Obstrutiva Crônica. Em resumo, a decisão: a) reconhece que a saúde pública deve ser garantida mediante políticas públicas, estando em debate o mínimo existencial à dignidade da vida humana; b) reconhece que os Poderes Estatais e a própria Sociedade Civil estão vinculados a esses indicadores norteadores da República; c) reconhece que, "no caso concreto, é a vida humana que está periclitando em termos de seu mínimo existencial (mantença da saúde), razão pela qual se impõe medidas de eficácia objetiva a resguardar e promover tal interesse público indisponível, tal como a de determinar que o Estado preste imediatamente a providência, quando for o caso efetivamente"; d) reconhece, fazendo menção a Alexy, que a matéria vertente precisa ser enfrentada com uma "ponderação de valores e princípios" que estão em jogo e que demandam abordagem à solução do caso: o bem jurídico vida da parte autora, envolvendo a moléstia de que está acoimada, correlato ao dever do Estado para com a saúde pública; o bem jurídico saúde pública de 
sobre a eficácia de normas constitucionais, senão também sobre a eficiência de tratamentos médicos, sua previsão no SUS etc.” (BALESTRA NETO, 2015, p. 104).

É retórica a discussão acerca da configuração da saúde como um direito fundamental. Muito mais desafiador é enfrentar os argumentos que permeiam os pedidos em torno desse direito, mormente quando levados às portas do Judiciário, necessitando de "condições de possibilidade de formação de um discurso de fundamentação, apto a abarcar todas as hipóteses de aplicação da norma que trata da obrigatoriedade por parte do Estado de fornecer saúde pública" (STRECK, 2017, p. 239, grifo do autor).

\section{CONSIDERAÇÕES FINAIS}

A atividade judiciária na condução de políticas públicas comumente se depara com a resolução de "casos difíceis", os quais desafiam a lógica procedimental estruturante da democracia, na medida em que se revelam como verdadeiras "zonas de penumbra" invocadoras de novos meandros de interpretação constitucional.

Nesses casos, não existe "receita pronta", capaz de orientar a intervenção judicial, apta a garantir a escorreita atividade interpretativa, bem como a "corrigir" as falhas administrativas: o que existe, em verdade, são critérios racionais, fundamentadores da validade das decisões. É através da ponderação dos princípios invocados no caso concreto que o ativismo judicial entra em contraste com a escolha desarrazoada do intérprete, muitas vezes voltada às suas preferências ou embasada por sua sensibilidade pessoal, desconsiderando o fato de que o juiz exerce uma função pública, e, portanto, voltada aos fins sociais, e não à sua subjetividade. Essa

toda a sociedade para com quem este mesmo Estado possui o dever de tutela; e) assinala, finalmente, que, em que pese a suposta emergência do pleito, a autora não trouxe aos autos qualquer elemento indicativo da efetiva urgência do pedido (a não ser o atestado médico), ou até mesmo que somente o medicamento postulado é eficaz no tratamento de que necessita, limitando-se a argumentar acerca da gravidade da doença e do dano irreparável que poderá sobrevir na falta de administração do tratamento. 'Assim, não há qualquer indicação acerca de grave periclitação à vida do paciente, a fim de ensejar o investimento público tão emergencial que sequer proporcione maior indicabilidade no âmbito do devido processo legal"' (grifos do autor). 
postura é um caminho escorregadio para a discricionariedade judicial, passível de condução ao seu excesso: a arbitrariedade.

Assim sendo, "o fato de não existir um método que possa dar garantia à 'correção' do processo interpretativo [...] não autoriza o intérprete a escolher o sentido que mais the convier [...]" (STRECK, 2017, p. 70), de forma a "politizar" o teor argumentativo das decisões judiciais, golpeando e subvertendo fatalmente a legitimidade democrática, além de promover a sucessão da "governança judicial" em políticas públicas. "O dever de motivação, mediante o emprego de argumentação racional e persuasiva, é um traço distintivo relevante da função jurisdicional e dá a ela uma específica legitimação" (BARROSO, 2008, p. 14).

Da análise do caso retratado relativo à saúde (recurso extraordinário $\mathrm{n}^{\circ} 566471 \mathrm{e}$ recurso especial $\mathrm{n}^{\circ}$ 1.657.156), denota-se um entendimento amparado por uma reflexão ponderada, onde a garantia de implementação do direito fundamental invocado torna-se viável através do estabelecimento de parâmetros decisórios, passíveis de racionalizar a respectiva prestação jurisdicional. A proporcionalidade dos elementos constitutivos da pretensão passa a ser considerada como fundamento de validade da decisão judicial (imprescindibilidade do medicamento não dispensado pelo SUS, incapacidade financeira do requerente e registro na ANVISA), configurando-se uma relação de razoabilidade entre o meio utilizado - a intervenção judicial - e o fim almejado - o direito fundamental social à saúde.

Em razão dessa proposta, o questionamento acerca do "financeiramente possível" merece ser combinado à seguinte indagação: é razoavelmente possível?

Em casos análogos, a atividade ponderada do Judiciário deve ainda observar a presença de fundamentações provindas de outras esferas do conhecimento, cujo apoio técnico pode tornar-se imprescindível ao deslinde causal, inibindo possíveis ingerências exacerbadas na autonomia administrativa.

De fato, a observância do caso concreto, dada a relevância e as singularidades que permeiam a tutela do direito social prestacional à saúde, torna-se imperiosa. Não se trata, portanto, de generalizar o manejo de pretensões individuais, mas de garantir diretrizes que cumpram com racionalidade os comandos constitucionais. No bojo da discussão acerca da 
intervenção judicial em políticas públicas, este torna-se um ponto sensível, de aguda relevância e propenso a acaloradas reflexões.

\section{REFERÊNCIAS}

APPIO, Eduardo. Controle judicial das políticas públicas no Brasil. 1. ed. Curitiba: Juruá Editora, 2012.

. Discricionariedade política do Poder Judiciário. 1. ed. Curitiba: Juruá Editora, 2008.

O controle judicial das políticas públicas no Brasil. 473 fls. Tese (Doutorado em Direito) - Universidade Federal de Santa Catarina, Centro de Ciências Jurídicas, Programa de Pós-graduação em Direito, Florianópolis, 2004. Disponível em: < https://repositorio.ufsc.br/handle/123456789/87373>. Acesso em: 05 ago. 2019.

BALESTRA NETO, Otávio. A jurisprudência dos Tribunais Superiores e o direito à saúde evolução rumo à racionalidade. Revista de Direito Sanitário, v. 16, n. 1, mar./jun. 2015, p. 87111. Disponível em: 〈http://www.periodicos.usp.br/rdisan/article/view/100025>. Acesso em: 19 jun. 2019.

BARROSO, Luís Roberto. Judicialização, Ativismo Judicial e Legitimidade Democrática. Revista (Sin)Thesis, Rio de Janeiro, v. 5, n. 1, 2012, p. 23-32. Disponível em: < https://www.epublicacoes.uerj.br/index.php/synthesis/article/view/7433>. Acesso em: 20 ago. 2018.

BRANDÃO, Rodrigo. A judicialização da política: teorias, condições e o caso brasileiro. Revista de Direito Administrativo - RDA, v. 263, maio/ago. 2013, p. 175-220. Disponível em: $<$ http://bibliotecadigital.fgv.br/ojs/index.php/rda/article/view/10648>. Acesso em: 19 jun. 2019.

BRASIL. [Constituição (1988)]. Constituição da República Federativa do Brasil. 24. ed. São Paulo: Saraiva, 2017. 
. Superior Tribunal de Justiça (1. Seção). Embargos de Declaração no Recurso Especial 1.657.156/RJ. Processual civil. Embargos de declaração no recurso especial. Estado do Rio de Janeiro. Recurso especial julgado sob a sistemática dos recursos repetitivos. Tema 106. Obrigatoriedade do poder público de fornecer medicamentos não incorporados em atos normativos do SUS. Art. 1.022 do CPC/2015. Ausência de vícios. Necessidade de esclarecimento. Vedação de fornecimento de medicamento para uso off label. Embargantes: Fatima Theresa Esteves dos Santos de Oliveira; Estado do Rio de Janeiro e União (assistente). Embargados: Estado do Rio de Janeiro e Fatima Theresa Esteves dos Santos de Oliveira. Relator: Min. Benedito Gonçalves, 12 de setembro de 2018 (recurso repetitivo). Disponível em: $<$ https://scon.stj.jus.br/SCON/jurisprudencia/toc.jsp?processo $=1657156 \& b=A C O R \&$ thesauru

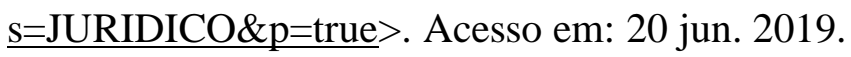

Recurso Especial 1.650.704/PE. Processual civil e administrativo. Sistema único de Saúde - SUS. Solidariedade entre os entes federativos. Legitimidade passiva ad causam. Fornecimento de medicamento que não consta na lista do SUS. Eficácia do medicamento. Conclusão do acórdão. Fatos e provas. Juízo de valor. Revisão. Súmula 7/STJ. Recorrente: União. Recorridos: Eduardo Luiz Souza de Lima e Estado de Pernambuco. Relator: Min. Herman Benjamin, 25 de abril de 2017. Disponível em: < https://ww2.stj.jus.br/processo/revista/inteiroteor/>. Acesso em: 20 jun. 2019.

Recurso Especial 1.682.973/RJ. Recurso especial. Administrativo e processual civil. Fornecimento de medicamento para tratamento de neoplasia maligna. Medicamento não dispensado pelo Instituto Nacional do Câncer. Medicamento ausente da grade de padronização. Direito à saúde. Pelo provimento do recurso especial. Recorrente: Amilton Alfazema. Recorridos: União; Estado do Rio de Janeiro e Município do Rio de Janeiro. Relator: Min. OG Fernandes, 5 de junho de 2018. Disponível em: <https://ww2.stj.jus.br/processo/revista/inteiroteor/>. Acesso em: 20 jun. 2019.

Recurso Extraordinário 566.471/RN. Constitucional. Ação de obrigação de fazer. Tutela antecipada. Preliminar de nulidade da sentença. Litisconsórcio passivo necessário. Transferência para o mérito. Fornecimento de medicamento de alto custo. Recusa do Estado em fornecê-lo. Impossibilidade. Afronta a direitos assegurados pela Constituição Federal. Obrigação do Estado apelante em promover o fornecimento de medicamento imprescindível ao 
tratamento de saúde da apelada. Manutenção da sentença de $1^{\circ}$ grau. Precedentes desta Egrégia Corte. Recurso conhecido e improvido. Recorrente: Estado do Rio Grande do Norte. Recorrido: Carmelita Anunciada de Souza. Relator: Min. Marco Aurélio, 15 de novembro de 2007 (repercussão geral). Disponível em: http://www.stf.jus.br/arquivo/cms/noticiaNoticiaStf/anexo/RE566471.pdf >. Acesso em: 20 jun. 2019.

Recurso Extraordinário 592.581/RS. Repercussão geral. Recurso do MPE contra acórdão do TJRS. Reforma de sentença que determinava a execução de obras na casa do albergado de Uruguaiana. Alegada ofensa ao princípio da separação dos poderes e desdobramento dos limites da reserva do possível. Inocorrência. Decisão que considerou direitos constitucionais de presos meras normas programáticas. Inadmissibilidade. Preceitos que têm eficácia plena e aplicabilidade imediata. Intervenção judicial que se mostra necessária e adequada para preservar o valor fundamental da pessoa humana. Observância, ademais, do postulado da inafastabilidade da jurisdição. Recurso conhecido e provido para manter a sentença cassada pelo Tribunal. Recorrente: Ministério Público do Estado do Rio Grande do Sul. Recorrido: Estado do Rio Grande do Sul. Relator: Min. Ricardo Lewandowski, 13 de agosto de 2015 (repercussão geral). Disponível em: < http://www.stf.jus.br/arquivo/cms/noticiaNoticiaStf/anexo/592581.pdf>. Acesso em: 19 jun. 2019.

BURGOS, Marcelo B.; SALlES, Paula M.; VIANNA, Luiz W. Dezessete anos de judicialização da política. Cadernos CEDES, n. 08, dez. 2006. Centro de estudos de Direito e Sociedade - CEDES - IUPERJ: Rio de Janeiro, 2006.

CONSELHO NACIONAL DE JUSTIÇA. Recomendação $n$. 31. Recomenda aos Tribunais a adoção de medidas visando melhor subsidiar os magistrados e demais operadores do direito, para assegurar maior eficiência na solução das demandas judiciais envolvendo a assistência à saúde. 30 de março de 2010. Disponível em: <http://www.cnj.jus.br/files/atos_administrativos/recomendao-n31-30-03-2010presidncia.pdf>. Acesso em: 20 jun. 2019.

DWORKIN, Ronald. Levando os direitos a sério. 3. ed. São Paulo: Editora WMF Martins Fontes, 2010. 
GRINOVER, Ada P. O controle das políticas públicas pelo poder Judiciário. Revista do Curso de Direito da Faculdade de Humanidades e Direito, v. 7, n. 7, 2010, p. 9-37. Disponível em: < https://www.metodista.br/revistas/revistasims/index.php/RFD/article/viewFile/1964/1969\&gt>. Acesso em: 05 ago. 2019.

MANCUSO, Rodolfo de C. Acesso à justiça - condicionantes legítimas e ilegítimas. São Paulo: Editora Revista dos Tribunais, 2011.

MÂNICA, Fernando B. Teoria da reserva do possível: direitos fundamentais a prestações e a intervenção do poder Judiciário na implementação de políticas públicas. Cadernos da Escola de Direito e Relações Internacionais da UniBrasil, jan./jul. 2008, p. 89-104. Disponível em: < http://revistas.unibrasil.com.br/cadernosdireito/index.php/direito/article/view/694>. Acesso em: 05 ago. 2019.

MELLO, Patrícia P. C. Precedentes Vinculantes nos Estados Unidos da América e no Direito Brasileiro: um estudo comparado. Revista de Direito Internacional, Brasília, v. 13, n. 3, 2016, p. 264-285. Disponível em: < https://papers.ssrn.com/sol3/papers.cfm?abstract_id=2922070>. Acesso em: 30 ago. 2019.

RAMOS NETO, Newton P. A construção do direito na jurisprudência do Supremo Tribunal Federal: limites e possibilidades no uso das sentenças aditivas. Observatório da jurisdição constitucional. Brasília: IDP, ano 2, 2008/2009.

SANTOS, Boaventura de S. Para uma revolução democrática da justiça. 3. ed. São Paulo: Cortez, 2011.

SARLET, Ingo W. A eficácia dos direitos fundamentais: uma teoria geral dos direitos fundamentais na perspectiva constitucional. 11 ed. Porto Alegre: Livraria do Advogado, 2012.

STRECK, Lenio L. Verdade e consenso. 6. ed. São Paulo: Saraiva, 2017.

SUPREMO TRIBUNAL FEDERAL. Principal. Disponível em: < http://www.stf.jus.br/portal/cms/verTexto.asp?servico=processoAudienciaPublicaSaude>. Acesso em: 20 jun. 2019. 
TRINDADE, André K. Garantismo versus neoconstitucionalismo: os desafios do protagonismo judicial em terrae brasilis. In: FERRAJOLI, Luigi; STRECK, Lenio L.; TRINDADE, André K. (orgs.). Garantismo, hermenêutica e (neo)constitucionalismo: um debate com Luigi Ferrajoli. Porto Alegre: Livraria do Advogado, 2012, p. 95-131.

Submetido em: 20/10/2019

Aceito em: 03/11/2019 